\title{
A Matching Multivalent Vaccine Candidate Combining Velogenic NDV Genotype VII and Variant IBV Protects Chicken from Virulent Challenge and Eliminates Virus Shedding
}

\author{
Asmaa Shawky ${ }^{1}$, Basem M. Ahmed ${ }^{2 *}$, Hala M. El-Makaky ${ }^{1}$, Ahmed A. El-Sanousi ${ }^{2}$ \\ ${ }^{1}$ Department of Newcastle Disease, Veterinary Serum and Vaccine Research Institute, Abbassia, Cairo, Egypt, 11381; \\ ${ }^{2}$ Department of Virology, Faculty of Veterinary Medicine, Cairo University, Giza, Egypt, 12211.
}

\begin{abstract}
Vaccination is the main preventive measure against infectious bronchitis virus (IBV) and Newcastle Disease virus (NDV) infections. Vaccination can partially protect against IBV because of the continuous emergence of variant strains. The aim of the current study is to evaluate the efficacy of multivalent inactivated vaccine candidate combining two IBV lineages (M41; GI-lineage) and (VarII; GI-23 lineage) along with NDV (genotype VII) using Montanide ISA-71 oil adjuvant against circulating variant IBV and velogenic NDV field strains. Our results revealed that the prepared vaccine candidate was sterile, safe, and potent due to its ability to stimulate the production of specific antibodies against IBV and NDV starting from 1-week post vaccination (WPV). The maximum levels of specific IBV ELISA antibody titers (2926) were observed at the sixth week post vaccination. HI antibodies against IBV reached its peak 5th WPV (9.2 $\log 2)$ while HI antibodies against NDV reached its peak 4 WPV $(9.5 \log 2)$. Vaccinated chickens showed $100 \%$ protection against challenge with virulent NDV, and variant IBV with complete absence of clinical signs and postmortem lesions compared to challenged non vaccinated groups. Our results revealed that the prepared vaccine candidate in this study is able to elicit good immune response, eliminate viral shedding, and provide complete protection against virulent challenge. Meanwhile, it is better to control both IBV and NDV outbreaks in a single shot consequently that will save time, effort and reduce stress during chicken vaccination.
\end{abstract}

Keywords | IBV GI-lineage, IBV GI-23 linage, NDV genotype VII, Inactivated multivalent vaccine, Virulent challenge, Efficacy, Shedding.

Received | September 07, 2020; Accepted | September 15, 2020; Published | November 15, 2020

*Correspondence | Basem M Ahmed, Department of Virology, Faculty of Veterinary Medicine, Cairo University, Giza, Egypt, 12211; Email: basem-ahmed@ cu.edu.eg

Citation | Shawky A, Ahmed BM, El-Makaky HM, El-Sanousi AA (2020). A matching multivalent vaccine candidate combining velogenic ndv genotype vii and variant ibv protects chicken from virulent challenge and eliminates virus shedding. Adv. Anim. Vet. Sci. 8(12): 1380-1387.

DOI | http://dx.doi.org/10.17582/journal.aavs/2020/8.12.1380.1387

ISSN (Online) | 2307-8316; ISSN (Print) | 2309-3331

Copyright $\odot 2020$ Ahmed et al. This is an open access article distributed under the Creative Commons Attribution License, which permits unrestricted use, distribution, and reproduction in any medium, provided the original work is properly cited.

\section{INTRODUCTION}

$\mathrm{I}^{\mathrm{n}}$ nfectious bronchitis is an acute, highly contagious, viral disease of chickens, caused by infectious bronchitis virus (IBV). IB is characterized primarily by respiratory signs in growing chickens, decreased egg quality and quantity in production hens. It can be nephro-pathogenic causing acute interstitial nephritis, urolithiasis, and mortality (Jackwood \& de Wit, 2013). IBV belongs to subgenus Igacovirus, genus gammacoronavirus, subfamily Orthocoronavirinae of the Coronaviridae family (ICTV, 2020). The only practical mean to control IB is through vaccination (Cavanagh, 2003). IBV was reported in Egypt for the first time in 1950 by Ahmed, (1954). Recently, many studies were conducted for the isolation of IBV from vaccinated and non-vaccinated chickens suffering from respiratory and or renal signs (Rohaim et al., 2019, 2020). Most IBV variants in Egypt belongs to GI-23 lineage with a high relatedness to Israeli variant II (VarII) (Rohaim et al., 2020; Valastro et al., 2016; Zanaty et al., 2016) to which current vaccination regimens are little effective (Abozeid et al., 2019). 
Newcastle disease (ND) is a highly contagious viral disease affecting various species of birds at any age, caused by Nerwcastle disease virus (NDV). NDV causes significant economic losses to the poultry industry worldwide due to high mortality and morbidity (Alexander, 2017; Musa et al., 2010). NDV (Avian orthoavulavirus 1) is the type species of orthoavulavirus genus in the avulavirinae subfamily of family paramyxoviridae (Dimitrov et al., 2019). Although all NDV are members of one serotype, antigenic and genetic diversity was observed between the NDV different genotypes (Miller et al., 2013). Control of NDV around the world depends mainly on vaccination using oil inactivated and lives vaccines (Alexander, 2017). Since the emergence of genotype VII in 2010-2011 in Egypt (Radwan et al., 2013) multiple outbreaks has been described in vaccinated poultry flocks (Saad et al., 2017; Tran et al., 2020).

Mixed infections of chickens with IBV and NDV or Avian Influenza (H5Nx or H9N2) without effective vaccination program lead to high economic losses (Hassan et al., 2016) (). Likewise, the circulation of multiple IBV genotypes hinder the efforts to control the disease by immunization (Cavanagh et al., 1997).

According to the latest OIE list of notifiable diseases (OIE, 2020) both IBV and NDV infections are notifiable, IBV and NDV outbreaks could be controlled by vaccination. Commonly used vaccines including live and inactivated genotype II vaccines against ND (Fawzy et al., 2020), live Mass-type and D274 or 793B variants besides inactivated IB vaccines (Abozeid et al., 2019; Al-Ebshahy et al., 2019). The failure of these vaccines to stabilize to situation of IB and ND in commercial farms is simply attributed to genetic and antigenic differences between used vaccine antigens and circulating viruses.

In this study, an inactivated multivalent vaccine candidate that matches circulating IB and ND viruses is prepared and evaluated with the hope to reduce commercial farm losses and to fill the gap in commercially available vaccines if commercialized. The candidate efficacy is compared to monovalent preparations and commercial vaccine representatives.

\section{MATERIALS AND METHODS}

\section{Ethics Statement}

All animal related procedures (breeding, handling, vaccination, and sampling) and experimental design were in accordance with VSVRI institutional instructions and guidelines for animal use in research.

\section{VIRUSES}

Velogenic NDV (KM288609.1_NDV-B7-RLQP-CHEG-12) was kindly provided by Central Laboratory for Evaluation of Veterinary Biologics (CLEVB). Variant IBV (Var-II) (KP729422_IBVS1/VSVRI_G9/Egy 013) and M41 IBV were kindly provided by Department of Poultry Vaccines Production Unit, Veterinary Serum and Vaccine Research Institute, Abbasia, Egypt. These viruses were used in the process of vaccines seed preparation as well as homologous challenge after vaccination.

\section{Candidate Vaccines Preparation}

Viruses were propagated in specific pathogen free (SPF) eggs according to the standard procedures (Principles of veterinary vaccine production, 2018). SPF eggs were obtained from Nile SPF Farm (Kom Oshiem, Fayom, Egypt).The harvested allantoic fluids were titrated (Reed and Müench, 1938). Formalin at final concentration of $0.1 \%$ was used for virus inactivation. Samples from each inactivated virus were tested for complete inactivation in 10- day-old SPF ECE's for two successive passages. Inactivated antigen bulks were mixed with Montanide ${ }^{\mathrm{TM}}$ ISA71 VG (SEPPIC, Paris, France) mineral oil-based adjuvant to prepare the vaccine candidate water-in-oil (W/O) emulsion. Meanwhile, monovalent inactivated NDV genotype VII vaccine, bivalent inactivated IBV (M41+ VarII), and multivalent inactivated IBV (M41+ VarII) and NDV genotype VII vaccine, were prepared and tested for sterility, and double-dose safety (Principles of veterinary vaccine production, 2018).

\section{Vaccination and Challenge Experiments}

Hundred 21-day old SPF chicks were used to evaluate the efficacy of the prepared vaccine candidates and to compare their efficacy to the commonly used commercial vaccine for NDV and IBV; inactivated Himmvac Dalguban N (plus) (KBNP, Korea) and Nobilis IB multi+ ND vaccine (Merck, USA). Chicks were divided into 7 groups, groups $1,2,3$, and $7(n=10)$, while groups 4,5 , and $6(n=20)$. Group vaccination, vaccines, and challenge data are illustrated in figure1. Groups 4, 5, and 6 were further divided into 2 subgroups at the challenge time, ten birds each, housed in separate isolators and challenged with respective viruses. Challenged chickens were observed for 2 weeks post challenge for any clinical signs or mortalities. Group 7 remained as a negative (non-vaccinated, non-challenged) control.

Protection percentage was evaluated based on the survival rate in case of NDV challenge and on ciliostasis score in case of IBV challenge (Pharmacopoeia, 2016). Briefly, half the chicks were euthanized on $7^{\text {th }}$ day post challenge (DPC) by an intravenous injection of $0.2 \mathrm{ml}$ of pentobarbital $(200 \mathrm{mg} / \mathrm{ml})$. Tracheas were removed and examined 
for ciliary activity and the maximum possible ciliostasis score (40) is given if there was complete ciliostasis (total lack of protection). The lower the score, the higher the level of protection provided by that vaccination program. An individual chick was recorded as protected against challenge if the ciliostasis score was less than 20 (Avian, 2018; 2018; Pharmacopoeia, 2016).

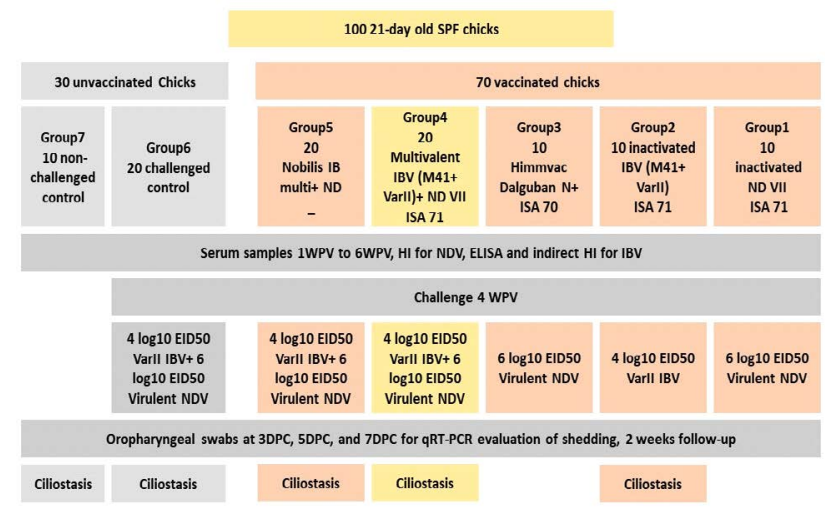

Figure 1: SPF chicken groups vaccination and challenge details. Chicks were vaccinated and challenged 28 days after vaccination according to their vaccination. Groups 4, 5 , and 6 were divided at the time of challenge into 2 groups ( $\mathrm{n}=10$ each), kept in separate isolators and challenged with either NDV or IBV. Swabs were collected 3, 5, and 7DPC for viral shedding determination. For IBV vaccinated groups ciliostasis test was performed 7DPC

\section{Serological Monitoring}

Sera were collected after vaccination on weekly basis for 6 weeks post vaccination (WPV). Hemagglutination inhibition (HI) assay was used to evaluate NDV antibody response in vaccinated groups. IDEXX IBV Ab ELISA Test (IDEXX laboratories, USA), and HI (using Var II-based IBV HA antigen, national laboratory for quality control of poultry production (NLQP), animal health research institute (AHRI), Dokki, Giza, Egypt) were used to evaluate the IBV antibody response in vaccinated and challenged chickens.

\section{Quantification of Viral Shedding using QRT- PCR}

Oropharyngeal swabs were collected from challenged chickens at 3-, 5- and 7-DPC and placed in $1 \mathrm{ml}$ physiological saline with antibiotic-antifungal mixture to evaluate the virus shedding using qRT-PCR.

Viral RNA was extracted using Qiamp viral RNA mini kit (Qiagen, GMBH) according to manufacturer instructions. Qunatitect probe RT-PCR kit (Qiagen, GMBH) was used to detect and relatively quantify the viral RNA in the collected swabs. Oligonucleotide primers and probes described previously were used to specifically detect the IBV and NDV RNAs (Meir et al., 2010; Wise et al., 2004). Swabs with higher CT values were considered to have lower virus load (low shedding) compared to challenged non vaccinated control birds while absence of amplification was considered as absence of shed virus (no shedding).

\section{Statistical Analysis}

One-way analysis of variance (ANOVA) was used to reveal whether the antibody titers differed significantly among the vaccinated chicken groups. A P-value of $\leq 0.05$ was considered statistically significant difference between groups.

\section{RESULTS}

\section{VACCINE STERILITy, AND SAFETy Evaluation}

The prepared vaccine candidates formed homogenous white emulsions with the adjuvant where the emulsion viscosity never exceeded 35 Pa.s. when measured with DV1 Digital Viscometer (AMETEK, Brookfield USA) at ambient temperature. Physical criteria remained acceptable after 1 month of candidate vaccines storage at $37^{\circ} \mathrm{C}$.

Vaccine candidates were found to be sterile and free from bacterial or fungal contaminants following recommended incubations on nutrient agar, Thioglycolate broth, and $\mathrm{Sa}^{-}$ bouraud's dextrose agar. Neither local nor systemic adverse effects nor reactions were noticed on chickens that received double doses of the prepared vaccine candidates to ensure their safety.

Serological Monitoring and Antibody Profiles Higher NDV antibody response was observed in chickens vaccinated with the prepared multivalent vaccine candidate (group 4). Group 4 immune response continued to increase and scored its peak $(9.5 \pm 0.5 \log 2) \mathrm{HI}$ titer by week 4 post vaccination, which was significantly higher than group 5 which was vaccinated by Nobilis IB Multi +ND (Merck, USA). However, on the sixth week post vaccination, all the vaccinated groups showed non-significant $\log 2 \mathrm{HI}$ titer differences (Figure 2a).

ELISA IBV antibody titers started to show evidence of vaccination $1 \mathrm{WPV}$. According to manufacturer, IDEXX IBV ELISA titers higher than 396 should be considered positive and indicative for vaccination or other exposure to IBV. Group 4 response was significantly higher $4 \mathrm{WPV}$ and 5 WPV (Figure 2b). While in group 5, the IBV response was significantly higher $3 \mathrm{WPV}$. At $6 \mathrm{WPV}$, group 4 recorded the highest IBV ELISA titer (2926 \pm 93.5$)$ which was significantly higher than group 5 but non-significantly higher than group 2 that received bivalent IBV (M41 + VarII) vaccine candidate (Figure 2b). 
IBV HI titers showed non-significant difference between IBV vaccinated groups (Figure 2c). Group 2 showed the highest IBV HI titers for all weeks except 5 WPV whereas Group 4 recorded the highest titer. Vaccinated groups showed statistically significant difference compared to control challenged non vaccinated group starting from $2^{\text {nd }}$ week post vaccination (Figure 2c).
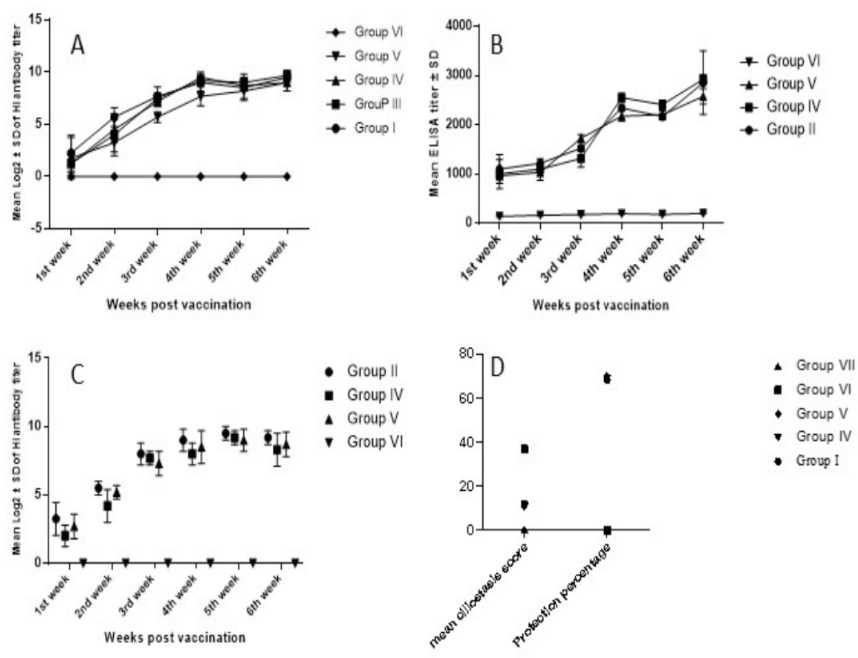

Figure 2: Serological monitoring and ciliostasis for vaccinated and challenged chicken groups. A) NDV HI titers in vaccinated groups. Response was fast, started oneweek post vaccination (wpv) and reached its paek 4wpv. B) IBV ELISA titers in IBV-vaccinated groups. Group IV antibodies were significantly higher than group V. The highest ELISA titer was recorded 6wpv in group IV sera. C) IBV HI titers, peak titers have been recorded $5 \mathrm{wpv}$. Vaccinated groups differed significantly from challenged non-vaccinated group (group VI) but not from each other. D) IBV protection percentages based on ciliary protection; vaccinated groups scored ciliostasis scores around 11 where scores $\leq 20$ are considered protective. Challenged nonvaccinated group ciliostasis score was 37 indicating lack of protection. Protection percentages in vaccinated groups was around 70 .

\section{Post-challenge Protection}

Following vNDV challenge, control challenged non-vaccinated chickens started to show depression and signs of disease $2^{\text {nd }}$ day post-challenge $(\mathrm{dpc})$. Mortalities started $3 \mathrm{dpc}$ and by day $6 \mathrm{dpc}$, all birds in the control challenged non vaccinated group were dead. Neither clinical signs nor mortalities were recorded in vaccinated groups with a $100 \%$ protection for all ND vaccinated groups. On the other hand, IB challenged non vaccinated control birds started to show disease signs and depression after challenge while vaccinated groups and control non-challenged group had no signs. Protection percentage was correlated to ciliary activity protection where group 5 showed the highest protection percentage of $70.3 \%$ compared to $69.18 \%$ in group
4 and $68.2 \%$ in group 2 (Figure $2 \mathrm{~d}$ ).

Vaccinated groups were able to significantly reduce the virus shedding compared to control challenged groups ( $\mathrm{Ta}-$ bles 1 and 2). In case of ND-vaccinated groups, group 1 and group 3 were able to prevent virus shedding by $5 \mathrm{dpc}$ while group 4 and group 5 were able to prevent the virus shedding by $7 \mathrm{dpc}$ (Table 1), while the IB-Vaccinated groups were able to prevent the virus shedding by $7 \mathrm{dpc}$ (Table 2). Our results revealed that the prepared vaccine candidate achieved $100 \%$ protection from apparent clinical signs and effectively reduced/eliminated the virus shedding.

Table 1 and Table 2.

\section{DISCUSSION}

IBV is circulating worldwide causing continuous outbreaks in chickens aided by its high genetic diversity, having the longest RNA genome equipped by high recombination rate (Abdel-Moneim, 2017). Majority of the Egyptian variant IBV strains are belonging to GI-23 lineage; closely related to Israeli variant II (Valastro et al., 2016; Zanaty et al., 2016). Usage of live variant IBV vaccines into the commercial poultry farms along with classical live IBV vaccines has shown some success to control the IBV ( J. J. De Wit et al., 2019; Sultan et al., 2019). However, the uncontrolled usage of live variant IBV vaccines in poultry vaccination regimes is a disaster that increase the IBV load and fastens its evolution (Toro et al., 2012). Similar protection could be achieved using inactivated classical and or variant IBV vaccines following live classical IBV vaccine prime. Inactivated vaccines are more expensive to produce but can induce longer and highly protective antibody responses without affecting the virus evolution (Brugh \& Siegel, 1978).

Genotype VII of NDV first emerged in China, 2000 (Qin et al., 2008; Tsai et al., 2004) then spread worldwide. Since its introduction to Egypt during 2010-2011 (Radwan et al., 2013), it continued to cause outbreaks and huge economic losses in commercial poultry sectors despite mass vaccination (Hassan et al., 2016; Orabi et al., 2017). Intensive usage of NDV Genotype II live and inactivated vaccines has failed in stabilizing the NDV situation within the commercial farms (Moharam et al., 2019; Sedeik et al., 2019; Sultan et al., 2020). Majority of these commercial vaccines always prevent the clinical manifestations but they still unable either to prevent the disease signs or to effectively reduce the virus shedding (Fawzy et al., 2020). Due to inability to attenuate NDV genotype VII, it is impossible by traditional means to prepare an attenuated vaccine except by genetic engineering (Cho et al., 2008; Hu et al., 2009) while the inactivated vaccines are still available as a safer and highly protective options (Fawzy et al., 2020; Sultan et al., 2020). 
Table 1: qRT- PCR Results of NDV shedding after challenge

\begin{tabular}{|c|c|c|c|c|c|c|c|}
\hline \multirow[t]{3}{*}{ Challenged groups } & \multicolumn{6}{|c|}{ Days post challenge (DPC) } & \multirow[t]{3}{*}{ Protection percent $\%$} \\
\hline & \multicolumn{2}{|l|}{3} & \multicolumn{2}{|l|}{5} & \multicolumn{2}{|l|}{7} & \\
\hline & Ct & $\begin{array}{l}\text { Shedding } \\
\text { quantity } \\
\text { (EID 50) }\end{array}$ & Ct & $\begin{array}{l}\text { Shedding } \\
\text { quantity } \\
\text { (EID 50) }\end{array}$ & Ct & $\begin{array}{l}\text { Shedding } \\
\text { quantity } \\
\text { (EID 50) }\end{array}$ & \\
\hline Group 1 & 27.84 & $6.44 \times 10^{2}$ & $\mathrm{No} C t$ & & No Ct & - & 100 \\
\hline Group 3 & 25.92 & $1.744 \times 10^{3}$ & No Ct & & No Ct & - & 100 \\
\hline Group 4 & 25.41 & $4.085 \times 10^{3}$ & 30.20 & $9.433 \times 10^{2}$ & No Ct & - & 100 \\
\hline Group 5 & 26.42 & $4,988 \times 10^{2}$ & 28.64 & $1.744 \times 10^{2}$ & $\mathrm{No} C t$ & - & 100 \\
\hline Group 6 & 15.33 & $2.740 \times 10^{6}$ & 17.21 & $2.977 \times 10^{7}$ & Ns & - & 0 \\
\hline Group 7 & No Ct & & $\mathrm{No} C t$ & & No Ct & & \\
\hline
\end{tabular}

Group 1: monovalent vNDV vaccine Group 3: Dalguban ${ }^{\circledR} \mathrm{N}+$ Group 4: multivalent (NDV\&IBV) vaccine

Group 5: Nobilis IB multi+ ND ${ }^{\circledR} \quad$ Group 6: challenged control Group 7: non-challenged control Ns: non-survival

Table 2: qRT- PCR Results of IBV shedding after challenge

\begin{tabular}{|c|c|c|c|c|c|c|c|}
\hline \multirow[t]{3}{*}{ Challenged group } & \multicolumn{6}{|c|}{ Days post challenge } & \multirow[t]{3}{*}{ Protection percent $\%$} \\
\hline & \multicolumn{2}{|l|}{3} & \multicolumn{2}{|l|}{5} & \multicolumn{2}{|l|}{7} & \\
\hline & $\mathrm{Ct}$ & $\begin{array}{l}\text { Shedding } \\
\text { quantity } \\
\text { (EID 50) }\end{array}$ & $\mathrm{Ct}$ & $\begin{array}{l}\text { Shedding } \\
\text { quantity } \\
\text { (EID 50) }\end{array}$ & $\mathrm{Ct}$ & $\begin{array}{l}\text { Shedding } \\
\text { quantity } \\
\text { (EID 50) }\end{array}$ & \\
\hline Group 2 & - & - & 31.00 & $8.613 \times 10^{2}$ & - & - & 100 \\
\hline Group 4 & 31.95 & $6.45 \times 10^{2}$ & 30.44 & $1.522 \times 10^{2}$ & - & - & 100 \\
\hline Group 5 & 33.03 & $1.172 \times 10^{1}$ & 31.12 & $6.905 \times 10^{2}$ & - & _ & 100 \\
\hline Group 6 & 20.56 & $7.962 \times 10^{4}$ & 19.94 & $1.222 \times 10^{5}$ & 18.19 & $4.092 \times 10^{5}$ & 0 \\
\hline Group 7 & 0 & 0 & 0 & 0 & 0 & 0 & \\
\hline
\end{tabular}

Montanide $^{\mathrm{TM}}$ range of water-in-oil adjuvants (Seppic, France) are based on light mineral oil combined with highly refined mannitol/oleic acid emulsifier for induction of humeral as well as cellular immune responses (Aucouturier et al., 2006). Montanide ${ }^{\mathrm{TM}}$ ISA 70 and ISA 71 have been used with multiple instances of success in poultry vaccines either experimentally or commercially (Ali et al., 2017; El-Jakee et al., 2020). Montanide ${ }^{\mathrm{TM}}$ ISA 71 is an improved mineral oil formula that preferentially stimulate Th1-type cell-mediated immunity and can induce similar IgG1 response but higher IgG2 response than ISA 70 (Dupuis et al., 2006). In a previous study, researchers proved that antibody response to Montanide ${ }^{\mathrm{TM}}$ ISA 71 adjuvanted vaccine reached its peak 8 weeks post vaccination and began to decrease gradually but remained above the protective level till 24 WPV (Ali et al., 2017). Control of NDV and IBV outbreaks mainly relies on biosecurity and vaccination (Mayahi et al., 2013). Likewise, proper diagnostic tools are essentially required to identify different IBV strains circulating in the field that will be helpful to select the suitable IBV seed virus for vaccine manufacture (J. J. De Wit et al., 2019; J. J. De Wit, 2000).
In this study, we prepared a vaccine candidate that contains classical Mass-type IBV (M41) and Variant IBV (VarII; circulating in Egyptian Poultry) (Ganapathy et al., 2015; Zanaty et al., 2016) along with a local isolate of velogenic NDV genotype VII to genetically match the field circulating IBV and NDV genotypes. The concept of genotype matched vaccine has aroused and proved its success after the failure of traditional vaccines to induce and maintain field satisfactory protection (Al-Ebshahy et al., 2019; Qin et al., 2008; Zhao et al., 2017). In our study, the selection of Montanide ${ }^{\mathrm{TM}}$ ISA 71 oil adjuvant relied mainly on its superiority to ISA 70 . The prepared multivalent and monovalent vaccine candidates were found to be physically acceptable, low viscosity and will save ease of application. Neither adverse reactions in chicken received double doses from the prepared vaccine candidates nor growth in the bacterial and fungal cultures ensuring the candidates safety and purity. Emulsions were found stable for 1 month at $37^{\circ} \mathrm{C}$, which is equivalent to at least 1 year at $4^{\circ} \mathrm{C}$.

Humeral immune response was evident against both IBV and NDV in vaccinated groups $1 \mathrm{WPV}$. The NDV antibodies correlate directly to the protection. Group 4 vac- 
cinated with the prepared multivalent vaccine exceeded protection 2WPV ( $\geq 4 \log 2$ ) (Figure $2 \mathrm{a}$ ) and its antibody level was significantly higher than group 5 vaccinated with commercial multivalent vaccines $3 \mathrm{WPV}$ and $4 \mathrm{WPV}$. This rapid response is an extra advantage for Montanide ${ }^{\mathrm{TM}}$ ISA 71 oil adjuvant. Following vNDV challenge, all groups were completely protected from clinical disease and mortality. Contrarily, protection from IBV could not be correlated with the antibody levels or protection from mortality (Raggi \& Lee, 1965). Antibodies against IBV were noticed $1 \mathrm{WPV}$, both ELISA and HI results were satisfactory and increased from week to week (Figures $2 \mathrm{~b}$ and $2 c$ ). The prepared vaccine candidate induced significantly higher ELISA titers in group 4 at 4, 5, and 6 WPV while no significant difference was observed with IBV HI results. This may be attributed to the nature of IBV antigen used to perform HI (Var II-based antigen) and it could be assumed that the difference is induced by M41 antigen in the vaccine. Absence of ciliostasis is a better and more dependable measure for IBV post-challenge protection (Darbyshire, 1985) especially if combined with reduced viral shedding. Ciliostasis scores for IBV-vaccinated and challenged groups was in the range of 11 compared to 37 of the non-vaccinated challenge group (Figure $2 \mathrm{~d}$ ).

Reduction of viral shedding is a core parameter for vaccine efficacy. If a vaccine is able to reduce or eliminate viral shedding; it could reduce virus load in the farm environment leading to decreased circulation, disease rates, and virus evolution (Zhao et al., 2017). Vaccinated groups with NDV vaccines showed reduced virus shedding and were able to eliminate virus shedding by $5 \mathrm{dpc}$ in monovalent inactivated NDV vaccinated groups (1 and 3), groups 4 and 5 eliminated shedding by $7 \mathrm{dpc}$ and this might be attributed to the nature of combined vaccines that might decrease immune system response to each vaccine antigen. While IB vaccinated groups eliminated virus shedding by $7 \mathrm{dpc}$. A previous study concluded that single dosage of monovalent variant IBV inactivated vaccine isn't enough to induce protection or to reduce shedding (Al-Ebshahy et al., 2019), Our data proved that the prepared IBV vaccine candidate that includes 2 different IBV antigens (classical and variant); is able to better stimulate the immune response in addition to the high efficacy of the oil adjuvant (Montanide ${ }^{\mathrm{TM}}$ ISA 71).

In conclusion, the prepared multivalent IB-ND vaccine candidate is considered as a locally prepared genotype matched vaccine candidate. Genotype matched viruses have highly similar genes that will express almost identical epitopes that would induce highly protective response and effectively reduce viral shedding. Montanide ${ }^{\mathrm{TM}}$ ISA 71 is a good oil adjuvant that can induce fast and protective response qualifying study vaccine to be used in all poultry production sectors. Multivalent vaccines always offer the advantages of lower labor and decreased stress to birds. Even though, the prepared vaccine was not superior to the commercial counterpart under experimental condition, it is expected to perform greater vaccine efficacy under field conditions within a well-designed poultry health program owing to its genetic similarity to currently circulating viral pathogens.

\section{ACKNOWLEDGMENTS}

Authors acknowledge colleagues at Newcastle Disease Department, VSVRI, Abbasia, Cairo for their great help during the work. Author also are grateful to Dr. Mohammed Rohaim for critically revising this article.

\section{CONFLICT OF INTEREST}

Authors declare that they have no competing interests.

\section{AUTHORS CONTRIBUTION}

AS performed the practical part and drafted the manuscript, BA analyzed results, drafted, and revised manuscript, AE, HM, and BA, supervised the work and conceived the study. All authors had read and approved the final manuscript.

\section{REFERENCES}

-Abdel-Moneim AS (2017). Coronaviridae: Infectious Bronchitis Virus. In J. Bayry (Ed.), Emerg. Re-emerg. Infect. Dis. Livest. (pp. 133-166). Springer International Publishing. https://doi.org/10.1007/978-3-319-47426-7_5

- Abozeid HH, Paldurai A, Varghese BP, Khattar SK, Afifi MA, Zouelfakkar S, El-Deeb AH, El-Kady MF, Samal SK (2019). Development of a recombinant Newcastle disease virus-vectored vaccine for infectious bronchitis virus variant strains circulating in Egypt. Vet. Res. 50(1): 12. https://doi. org/10.1186/s13567-019-0631-5

-Ahmed HN (1954). Incidence and treatment of some infectious viral respiratory diseases of poultry in Egypt. Ph.D. Thesis, Fac. Vet. Med. Cairo University, Giza, Egypt.

-Al-Ebshahy E, Abdel-Sabour M, Abas O, Yanai T (2019a). Protection conferred by a vaccine derived from an inactivated Egyptian variant of infectious bronchitis virus: a challenge experiment. Trop. Anim. Health Prod. https:// doi.org/10.1007/s11250-019-01898-y

-Al-Ebshahy E, Abdel-Sabour M, Abas O, Yanai T (2019b). Protection conferred by a vaccine derived from an inactivated Egyptian variant of infectious bronchitis virus: a challenge experiment. Trop. Anim. Health Prod. 51(7): 1997-2001. https://doi.org/10.1007/s11250-019-01898-y

-Alexander DJ (2017). Newcastle Disease, Other Avian Paramyxoviruses. Dis. Poult. Thirteenth Edition. https:// doi.org/10.1002/9781119421481.ch3

-Ali ZM, Hassan MAM, Hussein HA, Ahmed BM, El-Ghany El Sanousi AA (2017). Protective efficacy of combined 
trivalent inactivated ISA 71 oil adjuvant vaccine against avian influenza virus subtypes (H9N2 and $\mathrm{H} 5 \mathrm{~N} 1$ ) and Newcastle disease virus. Vet. World. 10(10). https://doi. org/10.14202/vetworld.2017.1212-1220

-Aucouturier J, Ascarateil S, Dupuis L (2006). The use of oil adjuvants in therapeutic vaccines. Vaccine. https://doi. org/10.1016/j.vaccine.2005.01.116

- Brugh M, Siegel HS (1978). Inactivated Newcastle disease vaccines: influence of virus concentration on the primary immune response. Poult. Sci. https://doi.org/10.3382/ ps.0570892

- Cavanagh D, Ellis MM, CookJKA (1997). Relationship between sequence variation in the S1 spike protein of infectious bronchitis virus and the extent of cross-protection in vivo. Avian Pathol. https://doi.org/10.1080/03079459708419194

- Cavanagh D (2003). Severe acute respiratory syndrome vaccine development: Experiences of vaccination against avian infectious bronchitis coronavirus. In Avian Pathol. https:// doi.org/10.1080/03079450310001621198

- Cho SH, Kwon HJ, Kim TE, Kim JH, Yoo HS, Park MH, Park YH, Kim SJ (2008). Characterization of a recombinant newcastle disease virus vaccine strain. Clin. Vacc. Immunol. https://doi.org/10.1128/CVI.00156-08

-Darbyshire JH (1985). A clearance test to assess protection in chickens vaccinated against avian infectious bronchitis virus. Avian Pathol. https://doi.org/10.1080/03079458508436252

- De Wit JJ (2000). Detection of infectious bronchitis virus. In Avian Pathol. https://doi.org/10.1080/03079450094108

- de Wit JJ, Sjaak, Malo A, Cook JKA (2019). Induction of IBV strain-specific neutralizing antibodies and broad spectrum protection in layer pullets primed with IBV Massachusetts (Mass) and 793B vaccines prior to injection of inactivated vaccine containing Mass antigen. Avian Pathol. https://doi. org/10.1080/03079457.2018.1556778

-Dimitrov KM, Abolnik C, Afonso CL, Albina E, Bahl J, Berg M, Briand FX, Brown IH, Choi KS, Chvala I, Diel DG, Durr PA, Ferreira HL, Fusaro A, Gil P, Goujgoulova GV, Grund C, Hicks JT, Joannis TM, Wong FYK (2019). Updated unified phylogenetic classification system and revised nomenclature for Newcastle disease virus. Infect. Genet. Evol.https://doi.org/10.1016/j.meegid.2019.103917

-Dupuis L, Ascarateil S, Aucouturier J, Ganne V (2006). SEPPIC vaccine adjuvants for poultry. Ann. New York Acad. Sci. https://doi.org/10.1196/annals.1373.024

-E1-Jakee JK, Moussa IM, Omran MS, Ahmed BM,Elgamal MA, Hemeg HA, Mubarak AS, Al-Maary KS, Kabli SA, Marouf SA, Haji Alhaaji J (2020). A novel bivalent PasteurellosisRHD vaccine candidate adjuvanted with Montanide ISA70 protects rabbits from lethal challenge. Saudi J. Biolog. Sci. https://doi.org/10.1016/j.sjbs.2019.12.042

-Fawzy M, Ali RR, Elfeil WK, Saleh AA, El-Tarabilli MMA (2020). Efficacy of inactivated velogenic newcastle disease virus genotype vii vaccine in broiler chickens. Vet. Res. Forum. https://doi.org/10.30466/vrf.2019.95311.2295

- Ganapathy K, Ball C, Forrester A (2015). Genotypes of infectious bronchitis viruses circulating in the Middle East between 2009 and 2014. Virus Res. https://doi. org/10.1016/j.virusres.2015.07.019

-Hassan KE, Shany SAS, Ali A, Dahshan AHM, El-Sawah AA, El-Kady MF (2016). Prevalence of avian respiratory viruses in broiler flocks in Egypt. Poult. Sci. https://doi. org/10.3382/ps/pew068

•Hu S, Ma H, Wu Y, Liu W, Wang X, Liu Y, Liu X (2009).
A vaccine candidate of attenuated genotype VII Newcastle disease virus generated by reverse genetics. Vaccine. https:// doi.org/10.1016/j.vaccine.2008.11.091

-ICTV (2020). Coronaviridae - Positive Sense RNA Viruses - Positive Sense RNA Viruses (2011) - International Committee On Taxonomy Of Viruses (ICTV). [online] International Committee on Taxonomy of Viruses (ICTV). Available at: <https://talk.ictvonline.org/ictv-reports/ ictv_9th_report/positive-sense-rna-viruses-2011/w/ posrna_viruses/222/coronaviridae> [Accessed 1 September 2020].

-Jackwood MW, de Wit S (2013). Infectious Bronchitis. In Dis. Poult. (pp. 139-159). https://doi.org/ doi:10.1002/9781119421481.ch4

-Mayahi M, Talazadeh F, Aslahi H (2013). Effect of the Commercial Mixed Live Newcastle Disease and Infectious Bronchitis Vaccines and the Use of Two Separate Vaccines Given Simultaneously on Systemic Antibody Responses. Iranian J. Virol. https://doi.org/10.21859/isv.7.3.17

-Meir R,Maharat O,Farnushi Y,Simanov L (2010). Development of a real-time TaqMan ${ }^{\circledR}$ RT-PCR assay for the detection of infectious bronchitis virus in chickens, and comparison of RT-PCR and virus isolation. J. Virol. Meth. https://doi. org/10.1016/j.jviromet.2009.09.014

- Miller PJ, Afonso CL, E1 Attrache J, Dorsey KM, Courtney SC, Guo Z, Kapczynski DR (2013). Effects of Newcastle disease virus vaccine antibodies on the shedding and transmission of challenge viruses. Develop. Comparat. Immunol. https:// doi.org/10.1016/j.dci.2013.06.007

-Moharam I, Razik AA, Sultan H, Ghezlan M, Meseko C, Franzke K, Harder T, Beer M, Grund C (2019). Investigation of suspected Newcastle disease (ND) outbreaks in Egypt uncovers a high virus velogenic ND virus burden in smallscale holdings and the presence of multiple pathogens. Avian Pathol. https://doi.org/10.1080/03079457.2019.1612852

- Musa IW, Abdu PA, Sackey AKB, Oladele SB, Lawal S, Yakubu IU (2010). Outbreak of velogenic viscerotropic newcastle disease in broilers. Int. J. Poult. Sci. https://doi.org/10.3923/ ijps.2010.1116.1119

- OIE (2020). OIE-Listed Diseases 2020: OIE - World Organisation For Animal Health. [online] Oie.int. Available at: <https:/www.oie.int/animal-health-in-theworld/oie-listed-diseases-2020/\#: :text=OIE-Listed\%20 diseases $\% 2$ C $\% 20$ infections $\% 20$ and $\% 20$ infestations $\% 20$ in $\% 20$ force $\% 20$ in, 9\%20Infection\%20with\%20Echinococcus\%20multilocularis\%20More\%20items...\%20> [Accessed 8 September 2020].

- Orabi A, Hussein A, Saleh AA, El-Magd MA, Munir M (2017). Evolutionary insights into the fusion protein of Newcastle disease virus isolated from vaccinated chickens in 2016 in Egypt. Arch. Virol. https://doi.org/10.1007/s00705-0173483-1

- Pharmacopoeia 2016. Avian Infectious Bronchitis Vaccine (live) (European Pharmacopoeia),1008-1010. Oie.int. 2018. Avian Infectious Bronchitis. [online] Available at: <https:// www.oie.int/fileadmin/Home/eng/Health_standards/ tahm/3.03.02_AIB.pdf> [Accessed 12 October 2020]. Oie. int. 2018. Principles Of Veterinary Vaccine Production. [online] Available at: <https:/www.oie.int/ fileadmin/ Home/eng/Health_standards/tahm/1.01.08_VACCINE_ PRODUCTION.pdf> [Accessed 12 October 2020].

- Qin ZM, Tan LT, Xu HY, Ma BC, Wang YL, Yuan X, Liu WJ (2008). Pathotypical characterization and molecular 
epidemiology of newcastle disease virus isolates from different hosts in China from 1996 to 2005 (Journal of Clinical Microbiology (2008) 46, 2, (601-611)). In J. Clin. Microbiol. https://doi.org/10.1128/JCM.00390-08

- Radwan MM, Darwish SF, El-Sabagh IM, El-Sanousi AA, Shalaby MA (2013). Isolation and molecular characterization of Newcastle disease virus genotypes II and VIId in Egypt between 2011 and 2012. Virus Genes. https://doi.org/10.1007/s11262-013-0950-y

- Raggi LG, Lee GG (1965). Lack of correlation between infectivity, serologic response and challenge results in immunization with an avian infectious bronchitis Vaccine. J. Immunol. (Baltimore, Md. : 1950).

- Reed IJ, Müench H (1938). A simple method of estimating 50 percent end-points. American J. Hyg.

- Rohaim MA, El Naggar RF, Abdelsabour MA, Mohamed MHA, El-Sabagh IM, Munir M (2020). Evolutionary analysis of infectious bronchitis virus reveals marked genetic diversity and recombination events. Genes. https://doi. org/10.3390/genes11060605

- Rohaim MA, E1 Naggar RF, Hamoud MM, Bazid AHI, Gamal AM, Laban SE, Abdel-Sabour MA, Nasr SAE, Zaki MM, Shabbir MZ, Zahran OK, Munir M (2019). Emergence and genetic analysis of variant pathogenic 4/91 (serotype 793/B) infectious bronchitis virus in Egypt during 2019. Virus Genes. 55(5): 720-725. https://doi.org/10.1007/s11262019-01693-9

- Saad AM, Samy A, Soliman MA, Arafa A, Zanaty A, Hassan MK, Sultan AH, Bazid AI, Hussein AH (2017). Genotypic and pathogenic characterization of genotype VII Newcastle disease viruses isolated from commercial farms in Egypt and evaluation of heterologous antibody responses. Archiv. Virol. https://doi.org/10.1007/s00705-017-3336-y

-Sedeik ME, Elbestawy AR, El-Shall NA, Abd El-Hack ME, Saadeldin IM, Swelum AA (2019). Comparative efficacy of commercial inactivated Newcastle disease virus vaccines against Newcastle disease virus genotype VII in broiler chickens. Poult. Sci. https://doi.org/10.3382/ps/pey559

-Sultan HA, Ali A, El Feil WK, Bazid AHI, Zain El-Abideen MA, Kilany WH (2019). Protective Efficacy of Different Live Attenuated Infectious Bronchitis Virus Vaccination Regimes Against Challenge With IBV Variant-2 Circulating in the Middle East. Front. Vet. Sci. 6: 341. https://doi. org/10.3389/fvets.2019.00341

- Sultan HA, Talaat S, Elfeil WK, Selim K, Kutkat MA, Amer SA, Choi KS (2020). Protective efficacy of the Newcastle disease virus genotype VII-matched vaccine in commercial layers. Poult. Sci. https://doi.org/10.1016/j.psj.2019.10.063

-Toro H, Pennington D, Gallardo RA, Van Santen VL, Van Ginkel FW, Zhang J, Joiner KS (2012). Infectious bronchitis virus subpopulations in vaccinated chickens after challenge. Avian Dis. https://doi.org/10.1637/9982-110811-Reg.1

-Tran GTH, Sultan S, Osman N, Hassan MI, VAN DONG H, Dao TD, Omatsu T, Katayama Y, Mizutani T, Takeda Y, Ogawa H, Imai K (2020). Molecular characterization of full genome sequences of newcastle disease viruses circulating among vaccinated chickens in Egypt during 2011-2013. J. Vet. Med. Sci. https://doi.org/10.1292/jvms.19-0623

- Tsai HJ, Chang KH, Tseng CH, Frost KM, Manvell RJ, Alexander DJ (2004). Antigenic and genotypical characterization of Newcastle disease viruses isolated in Taiwan between 1969 and 1996. Vet. Microbiol. https://doi. org/10.1016/j.vetmic.2004.09.005

-Valastro V, Holmes EC, Britton P, Fusaro A, Jackwood MW, Cattoli G, Monne I (2016). S1 gene-based phylogeny of infectious bronchitis virus: An attempt to harmonize virus classification. Infect. Genet. Evol. https://doi.org/10.1016/j. meegid.2016.02.015

-Wise MG, Wise MG, Suarez DL, Suarez DL, Seal BS, Seal BS, Pedersen JC, Pedersen, JC, Senne DA, Senne DA, King DJ, King DJ, Kapczynski DR, Kapczynski DR, Spackman E, Spackman E (2004). Development of a real-time reversetranscription PCR for detection of Newcastle disease virus RNA in clinical samples. J. Clin. Microbiol. https://doi. org/10.1128/JCM.42.1.329

-Zanaty A, Naguib MM, El-Husseiny MH, Mady W, Hagag N, Arafa AS (2016). The sequence of the full spike S1 glycoprotein of infectious bronchitis virus circulating in Egypt reveals evidence of intra-genotypic recombination. Archiv. Virol. https://doi.org/10.1007/s00705-016-3042-1

-Zhao J, Yang H, Xu H, Ma Z, Zhang G (2017). Efficacy of an inactivated bivalent vaccine against the prevalent strains of Newcastle disease and H9N2 avian influenza. Virol. J. https://doi.org/10.1186/s12985-017-0723-7 